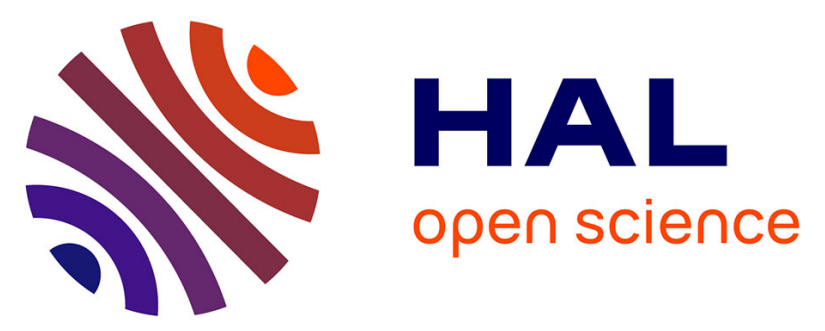

\title{
Fatigue Life of a SG Cast Iron under Real Loading Spectra: Effect of the Correlation Factor Between Bending and Torsion
}

\author{
Alexis Banvillet, Thierry Palin-Luc, Jean-François Vittori
}

\section{To cite this version:}

Alexis Banvillet, Thierry Palin-Luc, Jean-François Vittori. Fatigue Life of a SG Cast Iron under Real Loading Spectra: Effect of the Correlation Factor Between Bending and Torsion. Journal of ASTM International (JAI), 2004, 1 (8), pp.1-13. 10.1520/JAI19040 . hal-01372041

\author{
HAL Id: hal-01372041 \\ https://hal.science/hal-01372041
}

Submitted on 26 Sep 2016

HAL is a multi-disciplinary open access archive for the deposit and dissemination of scientific research documents, whether they are published or not. The documents may come from teaching and research institutions in France or abroad, or from public or private research centers.
L'archive ouverte pluridisciplinaire HAL, est destinée au dépôt et à la diffusion de documents scientifiques de niveau recherche, publiés ou non, émanant des établissements d'enseignement et de recherche français ou étrangers, des laboratoires publics ou privés. 
Alexis Banvillet, ${ }^{1}$ Thierry Palin-Luc, ${ }^{1}$ and Jean-François Vittori ${ }^{2}$

\title{
Fatigue Life of a SG Cast Iron under Real Loading Spectra: Effect of the Correlation Factor Between Bending and Torsion
}

\begin{abstract}
This paper deals with the effect on life of the desynchronism between two variable amplitude load sequences in combined bending and torsion. Experiments were carried out on smooth specimens made of the EN-GJS800-2 cast iron. The comparison between experimental lives and predicted ones with the following fatigue life calculation methods is presented: Smith-Watson-Topper, Fatemi and Socie (method proposed by Bannantine), Wang and Brown, Socie's proposal for high cycle fatigue, and Morel. If the scatter of experiments is considered, these experiments show a low effect of the correlation factor on life. All the simulated fatigue life calculation methods give good results for proportional loads, but their predictions are not good for non-proportional loads. Morel's proposal seems to be the best to predict life of the tested material with our non-proportional fatigue test conditions.
\end{abstract}

KEYWORDS: variable amplitude, multiaxial fatigue, correlation factor, life prediction, non-proportional loading

$\begin{array}{ll}\text { Nomenclature } & \\ C_{M t, M b} & \text { Correlation factor between } M b \text { and } M t \\ E & \text { Young modulus } \\ G & \text { Shear modulus } \\ K t & \text { Theoretical stress concentration factor } \\ M b, M t & \text { Bending and torsion moment } \\ N_{f} & \text { Number of cycles to fatigue crack initiation } \\ S_{M b}, S_{M t} & \text { Standard deviation of } M b \text {, respectively } M t \\ T_{\sigma, R M S} & \text { Root mean square value of the macroscopic resolved shear stress } \\ b, b_{0} & \text { amplitude } \\ c, c_{0} & \text { Normal and shear fatigue strength exponent } \\ k_{1} & \text { Normal and shear fatigue ductility exponent } \\ k_{2} & \text { Material parameter used by Fatemi and Socie } \\ p, q, r & \text { Material parameter used by Socie } \\ s & \text { Parameters of the Morel method } \\ \gamma_{a} & \text { Material parameter used by Wang and Brown } \\ & \text { Shear strain amplitude }\end{array}$

Manuscript received 23 April 2002; accepted for publication 21 November 2002; published September 2004. Presented at ASTM Symposium on Fatigue Testing and Analysis Under Variable Amplitude Loading Conditions on 29-31 May 2002 in Tours, France; P. C. McKeighan and N. Ranganathan, Guest Editors.

${ }^{1}$ Ph.D. Student (now Dr.) and Senior Lecturer, respectively, ENSAM-Laboratoire Matériaux Endommagement Fiabilité et Ingénierie des Procédés (EA 2727), Esplanade des Arts et Métiers, F-33405 Talence Cedex, France.

${ }^{2}$ Engineer, RENAULT, Technocentre, Dir. Ingénierie des Matériaux, Sce 64130, API: TCR LAB 035, 1 Av. Golf, F-78288 Guyancourt, France. 


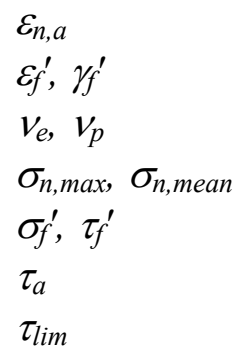

Strain amplitude normal to the critical plane

Normal and shear fatigue ductility coefficient

Elastic Poisson coefficient, respectively plastic

Maximum and mean normal stress on the critical plane

Tensile and shear fatigue strength coefficient

Shear stress amplitude experiencing on the critical plane

Shear stress treshold of non plastic flow in the Morel model

\section{Introduction}

Fatigue life prediction of materials and components under variable amplitude loading, especially under multiaxial stress states, is always an open question. Indeed, many components of a car or a plane, for instance, are loaded by variable amplitude sequences generating multiaxial stress states. There is not a general agreement on the life calculation method able to predict life in such non-proportional load conditions. The aim of this paper is to investigate the effect on life of the desynchronism between two variable amplitude load sequences in combined bending and torsion. The material tested is the EN-GJS800-2 cast iron, and the loading sequences are coming from service records. The comparison between predicted and experimental lives is done for the following fatigue life calculation methods: Smith-Watson-Topper [1], Fatemi and Socie [2] (method proposed by Bannantine [3,4]), Wang and Brown [5,6], Socie's proposal for high cycle fatigue [7], and Morel [8,9].

In the first section of this paper, test conditions, experiments, and fatigue data are detailed. In the second section, fatigue life calculation methods are described briefly with their simulation conditions. Then, fatigue data and life predictions are compared and discussed.

\section{Experiments}

\section{Material and Specimens}

All experiments were carried out on smooth specimens $(\mathrm{Kt}($ bending $)=1.07$, $\mathrm{Kt}($ torsion $)=1.04)$ made of the EN GJS 800-2 spheroidal graphite cast iron. These specimens are illustrated in Fig. 1. The microstructure of this material has a bull's eye appearance: the spheroids of graphite are surrounded by ferrite; spheroids and ferrite zone are included in a pearlitic matrix. After the treatment of heating and holding at $920^{\circ} \mathrm{C}$ for $1-2 \mathrm{~h}$, slow cooling at $870^{\circ} \mathrm{C}$ for $3-4 \mathrm{~h}$, then air cooling, the main mechanical characteristics of this cast iron are as follows: Young's modulus $=164.9 \mathrm{GPa}, \quad$ Poisson's ratio $=0.275$, Proof $(0.02 \%)$ stress $=320 \mathrm{MPa}$, Proof stress $(0.2 \%)=462 \mathrm{MPa}$, maximum tensile strength $=795 \mathrm{MPa}$, elongation after failure $=9 \%$, endurance limit in fully reversed plane bending $=294 \mathrm{MPa}$, endurance limit in fully reversed torsion $=220 \mathrm{MPa}$. This is the same material as used by PalinLuc et al. [10] (see this reference for other details). 


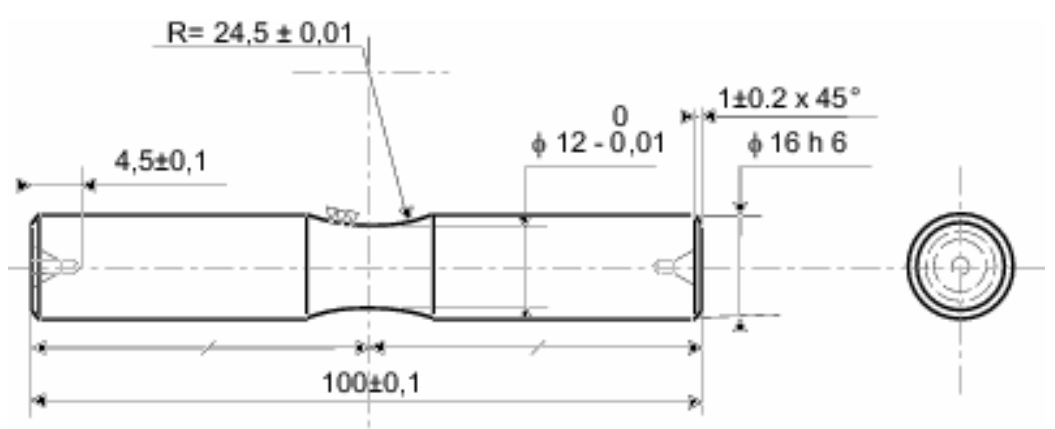

FIG. 1-Specimen geometry (dimensions in mm).

\section{Fatigue Testing Machine}

Fatigue tests were carried out with a closed-loop servo-hydraulic multiaxial fatigue testing machine designed in our laboratory and able to impose simultaneous bending and torsion moments [11]. The time evolution (i.e., shape) of the loading signal is servo-controlled in real time on each actuator (bending and torsion) together with the synchronism between each loading signal. This means that the evolution of the bending and torsion moments versus time is controlled and equal to the recorded sequence; the servo-control precision is $\pm 2.5 \mathrm{Nm}$. Thus, the power spectral density (PSD) of the loading applied on the specimen is very close to the PSD of the recorded sequence [12]. The peaks and valleys of the sequence are also servo-controlled. It must be pointed out that if only the peaks and valleys of the signal were servo-controlled, the PSD of the load signal and its time evolution would not have been like the recorded sequence. The loading sequence was repeated until fatigue macro-crack initiation, which was detected by a $10 \%$ drop of the specimen stiffness. The size of the detected fatigue crack for random sequences is approximately $2 \mathrm{~mm}$ in depth on the specimen [12].

\section{Loadings}

Experiments were carried out in four point plane bending, in torsion and in combined plane bending and torsion under a random loading sequence (Fig. 2) recorded from strain gauges stuck on a car suspension arm. This sequence, representing a special type of road, is short in time (20 s); nevertheless this is representative of a real severe loading spectrum. A signal analysis of the total recorded sequence ( $34 \mathrm{~s}$ equivalent to a road of $200 \mathrm{~m}$ in length) shows that the bandwidth of this signal is $50 \mathrm{~Hz}$ (Fig. 3), and its "correlation length" (minimum time window for stationary conditions) is around $1 \mathrm{~s}$, which is very short compared with $20 \mathrm{~s}$. One can conclude that the $20 \mathrm{~s}$ of the sequence are long enough to be representative (for a spectral point of view) of the total sequence. The loading applied to the specimens is thus stationary and "pseudo-random." This sequence was applied on the specimens with a null mean value.

The load sequence is Gaussian, as shown in Fig. 4. Its mean value is very close to zero, and the standard deviation of the normalized load is around 0.32 .

This short sequence contains around 370 cycles according to the Rainflow cycle counting method (AFNOR standard NF03-406, "Fatigue sous sollicitations d'amplitude variable. Méthode Rainflow de comptage"). The cycles with the highest amplitude are distributed around a zero mean value (Fig. 5). Nevertheless, there are some low amplitude cycles with a great mean value. This kind of loading could discriminate the correction of mean value proposed by the different life calculation methods. 


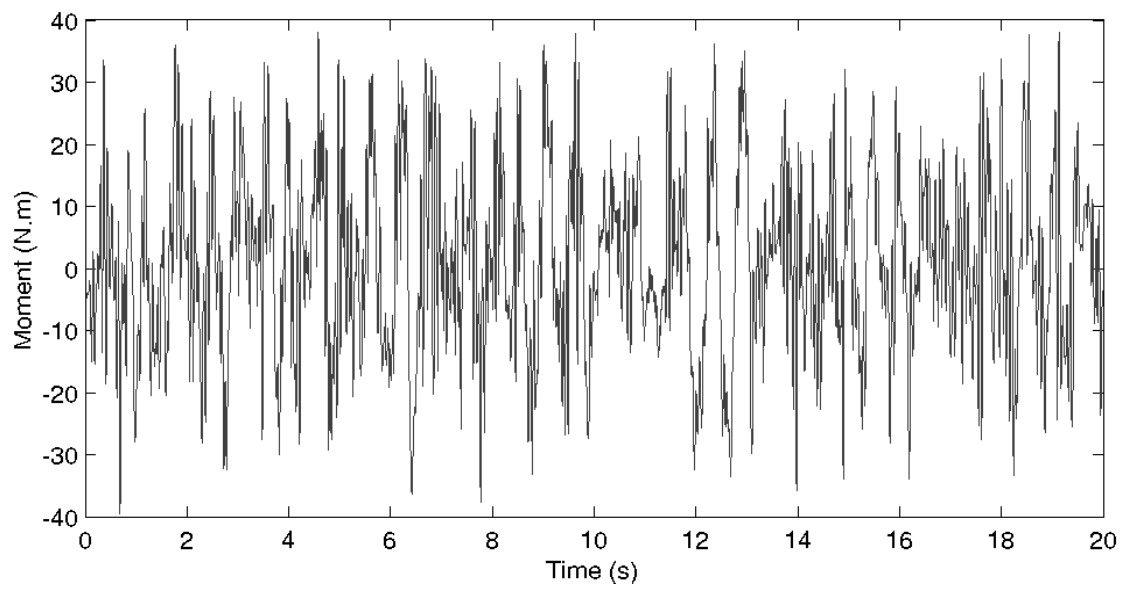

FIG. 2-Load sequence of the signal applied to the specimens, in plane bending, in torsion, and in combined plane bending and torsion.

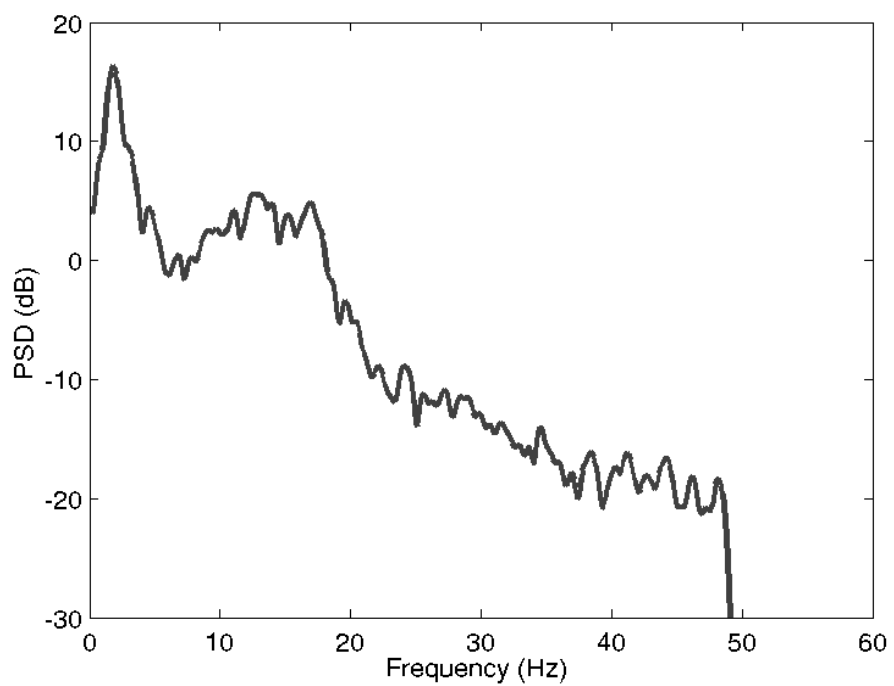

FIG. 3-Power Spectral Density (PSD) of the signal applied to the specimens, in plane bending, in torsion, and in combined plane bending and torsion.
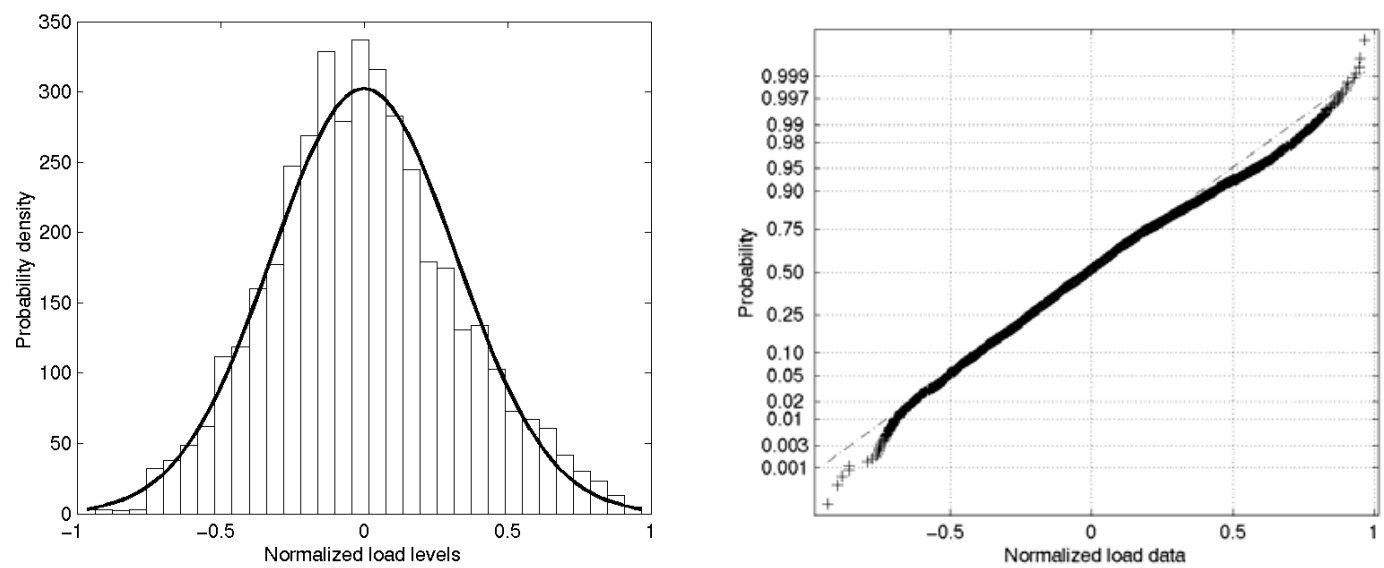

FIG. 4-Probability density (on the left-dark line is a theoretical gaussian distribution) and probability repartition of the normalized load sequence (on the right). 


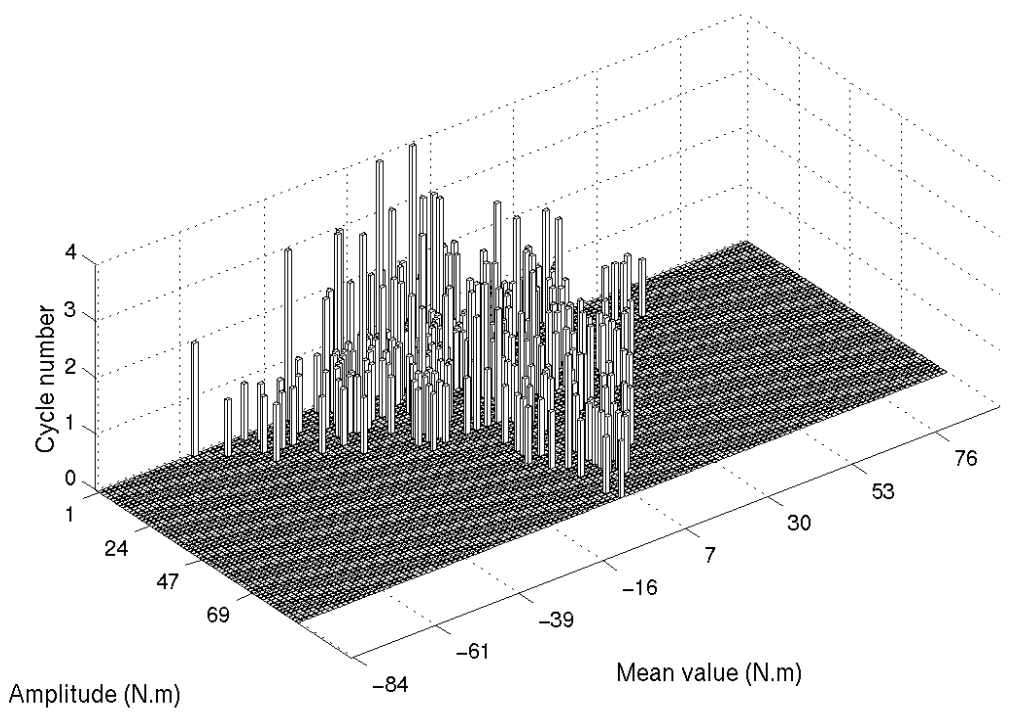

FIG. 5-Rainflow cycle number versus mean and amplitude moment values (torsion case).

Two types of fatigue tests under combined loadings were done. First, the same loading sequence (Fig. 2) was applied simultaneously in bending and in torsion with different ranges. The bending and torsion moments were synchronous. Second, the bending and torsion moments follow the same loading sequence but out of synchronism.

Two different de-synchronisms between each loading were tested. For each case the maximum nominal stresses (elastic stresses) are the same because tests were load controlled. The local maximum and minimum stresses on all the sequence are given in Table 1 with the root mean square value of the normal and shear stresses. Maximum and minimum stresses were computed with an elastic-plastic finite element analysis [12].

TABLE 1-Loading conditions (stresses in MPa).

\begin{tabular}{cccccccc}
\hline Loading & $\mathrm{C}_{\mathrm{Mt}, \mathrm{Mb}}$ & $\sigma_{\max }$ & $\tau_{\max }$ & $\sigma_{\min }$ & $\tau_{\min }$ & $\sigma_{\mathrm{RMS}}$ & $\tau_{\mathrm{RMS}}$ \\
\hline Torsion & $\ldots$ & 0 & 254 & 0 & -231 & 0 & 82 \\
Plane bending & $\ldots$ & 363 & 0 & -313 & 0 & 130 & 0 \\
P1. bend. + To & 0.04 & 240 & 186 & -248 & -172 & 90 & 56 \\
Pl. bend + To & 0.62 & 240 & 186 & -248 & -172 & 90 & 56 \\
Pl. bend + To & 0.94 & 225 & 167 & -233 & -147 & 90 & 56 \\
\hline
\end{tabular}

To characterize the load desynchronism between $M t$ and $M b$, the correlation factor, $C_{M t, M b}$, was computed for the complete sequence (1).

$$
C_{M t, M b}=\frac{\operatorname{cov}(M t, M b)}{S_{M t}, S_{M b}}
$$

where $\operatorname{cov}(M t, M f)$ is the covariance of the torsion moment $M t$ and the bending moment $M b . S_{M b}$ and $S_{M t}$ are, respectively, the standard deviation of $M b$ and $M t$. When $C_{M t, M b}$ is equal to 1 , the two loads are synchronous, there is a perfect correlation between them, and the load path is 
proportional; when $C_{M t, M b}$ is equal to 0 , there is no correlation between $M t$ and $M b$. Figure 6 shows the different load paths corresponding to the multiaxial loadings applied to the specimens.
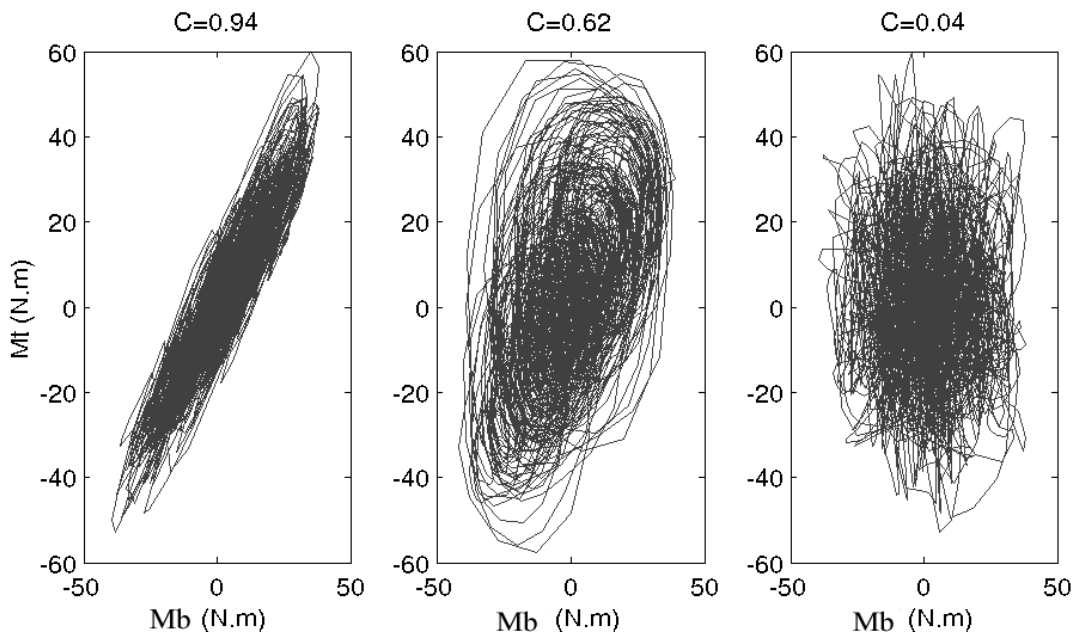

FIG. 6-Load paths applied on the specimens in combined bending and torsion with different correlation factors $C_{M t, M b}$ (noted $C$ ).

\section{Fatigue Test Results}

The fatigue test results are given in Table 2. $N f_{0.5}$ is the median fatigue life, $N f_{0.16}$ and $N f_{0.84}$ are, respectively, the fatigue lives for a failure probability of 0.16 and 0.84 . The number of specimens is different because test time was very long.

TABLE 2-Results of the fatigue tests (Nf in number of sequences).

\begin{tabular}{cccccc}
\hline Loading & $\mathrm{C}_{\mathrm{Mt}, \mathrm{Mb}}$ & $\mathrm{Nf}_{0.5}$ & $\mathrm{Nf}_{0.16}$ & $\mathrm{Nf}_{0.84}$ & $\mathrm{Nb}$. specimen \\
\hline Torsion & $\ldots$ & 19020 & 12688 & 28513 & 10 \\
Plane bending & $\ldots$ & 11268 & 5989 & 21270 & 10 \\
Plane bend. + To & 0.04 & 49760 & 21782 & 113677 & 4 \\
Plane bend + To & 0.62 & 9587 & 3630 & 25322 & 7 \\
Plane bend + To & 0.94 & 16496 & 6269 & 43406 & 8 \\
\hline
\end{tabular}

\section{Life Calculation Method Analysis and Discussion}

\section{Brief Literature Review}

At present, the main fatigue models presented in literature are based on critical plane approaches. Nevertheless, regarding all the different proposals, the choice of a particular method is not always evident. Models have to be chosen depending on both the material and the observed failure mode. Socie's works on different steels [7] also underlines that the cracking mode may be dependent on the fatigue regime. Nowadays it is usually accepted that for ductile steels, fatigue cracks initiate along the persistent slip bands (local plasticity phenomenon) generated by local shear stress. On the other hand, for brittle materials, crack initiation phase is very short, and the more adapted criteria are based on the maximum tensile stress $[13,14]$. To 
take into account all the material behavior, many authors usually propose using a combination of shear and tensile stresses or strains calculated on a critical plane. Different criteria are tested hereafter:

- a strain based one developed for low cycle fatigue (LCF) regime

- stress based approaches proposed for high cycle fatigue (HCF) regime

- a stress-strain one to predict life whatever the regime is

In the following models, except for the Morel's one, the damage parameter used has been proposed originally for cyclic loading, then used by some authors for variable amplitude multiaxial loading [4].

Fatemi and Socie's Model [2-4]_-When fatigue crack initiation is dominated by plastic shear strains, these authors recommend the use of the FS model (2). For each material plane oriented by the unit normal vector $\vec{n}$, the cycle counting method is applied on two variables: the shear strains $\varepsilon_{x^{\prime} n}(t)$ and $\varepsilon_{y^{\prime} n}(t)$ (see Fig. A.1 in the Appendix: coordinate system definition).

$$
\gamma_{a}\left(1+k_{1} \sigma_{n, \max } / \sigma_{y}\right)=\frac{\tau_{f}^{\prime}}{G}\left(2 N_{f}\right)^{b 0}+\gamma_{f}^{\prime}\left(2 N_{f}\right)^{c 0}
$$

The right-hand side of Eq 2 is the description of the strain-life Manson-Coffin curve in torsion. The term on the left-hand side represents the damage parameter on the plane experiencing the largest range of the shear strain (critical plane). Finally, life is computed on the critical plane where the total damage is maximum. In this term, $k_{1}$ is a material parameter identified by fitting uniaxial against pure torsion fatigue data. This parameter is varying with finite life $N_{f}$. When the strain-life Manson-Coffin curve is not known in torsion, FS propose to approximate this curve from the tensile strain-life curve [2].

Smith, Watson, and Topper's Model (SWT) [1] - This model was proposed for the first time in 1974 to take into account the mean stress effect on the tensile fatigue strength. Recently, Socie observed [7] that short fatigue cracks grow on the plane perpendicular to the maximum principal stress and strain (Mode I). He recommends using the SWT damage parameter, $\varepsilon_{n, a} \sigma_{n, \max }$ (3) calculated on the maximum normal strain plane. For each material plane, the cycle counting method is applied on the normal strain $\varepsilon_{n}(t)$ (see Fig. A.1 in the Appendix). The critical plane is the plane where the damage is maximum (total Miner sum is maximum).

$$
\varepsilon_{n, a} \sigma_{n, \max }=\frac{\sigma_{f}^{\prime 2}}{E}\left(2 N_{f}\right)^{2 b}+{\sigma_{f}^{\prime}}_{f} \varepsilon_{f}^{\prime}\left(2 N_{f}\right)^{b+c}
$$

This criterion, which does not express any influence of the shear stress on life, is more adapted to brittle materials. For a finite life $N_{f}$, the ratio between the tensile and torsional fatigue limits is constant whatever the material is and equal to $(1+v)^{0.5}$, which corresponds quite well to the GGG40 and GGG60 cast irons [13,14] and the studied one.

Socie's Proposal for HCF Region [7]-According to the previous author for HCF and a ductile material, most of the fatigue life is consumed by crack initiation on planes where the shear stress amplitude is maximum. In this case, Socie proposes the stress based approach (4). The cycle counting algorithm is applied for each material plane on both the shear stresses $\tau_{x^{\prime} n}(t)$ 
and $\tau_{y^{\prime} n}(t)$. For each one of these variables, the critical plane is that experiencing the largest range of the corresponding shear stress. Life is finally computed on the critical plane where the total damage is maximum.

$$
\tau_{a}+k_{2} \sigma_{n, \max }=\tau_{f}{ }^{\prime}\left(2 N_{f}\right)^{b 0}
$$

The right-hand side of Eq 4 is the elastic part of the strain-life. The terms of the left-hand side represent the damage parameters defined on the plane experiencing the largest range of the cyclic shear stress. $k_{2}$ is a material parameter identified by fitting Eq 4 with tension and torsion fatigue data.

Wang and Brown's Model [5,6] — Wang and Brown developed a model restricted first to LCF and MCF according to the hypothesis that fatigue crack growth is controlled by the maximum shear strain with an important additional role of the normal strain excursion over one reversal of the shear strain acting on the plane where the shear strain is maximum. This proposal was extended to HCF (5) by taking into account the mean stress effect on fatigue lifetime by using the Morrow correction. The cycle counting algorithm is applied for each material plane on both the shear stresses $\varepsilon_{x^{\prime} n}(t)$ and $\varepsilon_{y^{\prime} n}(t)$. For each one of these variables, the critical plane is this experiencing the largest range of the corresponding shear strain. Life is finally computed on the critical plane where the total damage is maximum.

$$
\gamma_{a}+S . \delta \varepsilon_{n}=\left(1+v_{e}+S\left(1-v_{e}\right)\right) \frac{{\sigma_{f}^{\prime}}_{f}-2 \sigma_{n, \text { mean }}}{E}\left(2 N_{f}\right)^{b}+\left(1+v_{p}+S\left(1-v_{p}\right)\right) \varepsilon_{f}^{\prime}\left(2 N_{f}\right)^{c}
$$

$\delta \varepsilon_{n}$ is the normal strain excursion between two turning points (consecutive extrema) of the shear strain versus time acting on the maximum shear strain plane. $S$ is a material parameter identified by fitting tension against torsion fatigue data.

Morel Approach [8,9]-Morel developed a model for polycrystalline metals in HCF based on the accumulation of mesoscopic plastic strain. He assumes that crack initiation occurs by failure of the most stressed grains along the plane experiencing the maximum value of the parameter $T_{\sigma, R M S}$ defined by (6). This author shows that this quantity is proportional to an upper bound value of the cumulated mesoscopic plastic strain.

$$
T_{\sigma, R M S}(\theta, \phi)=\sqrt{\int_{0}^{2 \pi} T_{R M S}^{2}(\theta, \phi, \psi) d \psi}
$$

$T_{\sigma, R M S}$ is the root mean square of the macroscopic resolved shear stress amplitude acting on a line determined by the angle $\psi$ from fixed axis in the plane defined by its angles $\theta$ and $\phi$ [7]. According to the author, the number of cycles to crack initiation $N f$ follows the analytical Eq 7.

$$
N_{f}=p \ln \left(\frac{\tau_{a}}{\tau_{a}-\tau_{\lim }}\right)+q\left(\frac{\tau_{\lim }}{\tau_{a}-\tau_{\lim }}\right)-\frac{r}{\tau_{a}}
$$

In this equation $p, q$, and $r$ are functions of the hardening and softening material parameters, assuming that the behavior of each grain of the material can be described by a three phases law (hardening, saturation, and softening). They can be identified by fitting an S-N curve or 
following the procedure described in [9]. $\tau_{a}$ is the amplitude of the macroscopic resolved shear stress on the critical plane. $\tau_{\text {lim }}$ is the generalized fatigue limit depending on the loading and two endurance limits [9]. Note that for the Morel method, the damage accumulation is done step by step, so calculated life is sensitive to the order of the stress levels.

\section{Life Calculation Procedure Used in This Study [12]}

In the present paper, the material parameters $k_{1}$ and $k_{2}$ are the mean values of these parameters for life varying between $10^{5}$ and $10^{6}$ cycles. Kim and Park [15] observed for different materials that these values are varying with the lifetime and may influence the predictions. Thus, the method to identify them also could have a non-negligible role.

Strain and stress histories are computed from the loading history (bending and torsion moments versus time) by using an elastic-plastic finite element analysis, with the hypothesis that the material (EN GJS 800-2) follows an isotropic hardening rule. Then, on the cycle counting variable of each model, the rainflow cycle counting method was used to extract the cycles from the stress or strain time history. For each extracted cycle $i$, the elementary damage $d_{i}$ (according to each author) is calculated and accumulated by using the Palmgren-Miner rule. This damage parameter also is computed on each material plane $P_{\vec{n}}$, oriented by the unit normal vector $\vec{n}$, in order to look for the critical plane $\mathrm{P}_{\overrightarrow{\mathrm{n}}_{\mathrm{c}}}$, which depends on the method. Damage is accumulated by using the same law, with the hypothesis $D=\Sigma_{i} d_{i}=1$ when the fatigue crack initiates. The Morel calculation method was applied using the step by step damage accumulation according to its author.

\section{Comparison Between Predictions and Experiments}

As illustrated in Fig. 7, prediction methods (Table 3 ) seem to be very sensitive to the loading path, especially for the very low correlation factor: $C=0.04$. The ratios between simulated and experimental life reach the value of 34 . Indeed, the predictions are inside the following intervals:

- SWT: Npred $\in[\mathrm{Nexp} / 1.1 ; 7.7 \mathrm{Nexp}]$,

- WB: Npred $\in[\mathrm{Nexp} / 34.6 ; 4.3 \mathrm{Nexp}]$,

- So: $\mathrm{Npred} \in[\mathrm{Nexp} / 5.3 ; 16.2 \mathrm{Nexp}]$.

- FS: $\quad$ Npred $\in[\mathrm{Nexp} / 4.5 ; 7.1 \mathrm{Nexp}]$

- M: $\quad$ Npred $\in[\mathrm{Nexp} / 1.7 ; 5.5 \mathrm{Nexp}]$

For any non-proportional loading tests, the errors are higher than a factor of two, either in the safety area or in the unsafe one. This may be explained by the fact that all the tested methods were mainly developed for ductile materials, while the spheroidal graphite cast iron EN GJS 800-2 is not ductile. Wang-Brown and Fatemi-Socie give correct predictions, but they are much more scattered than Morel's proposal, whose predictions for the tested material with our non-proportional fatigue test conditions are less scattered compared with the experiments. Its predictions are inside the smallest interval $[\mathrm{Nexp} / 1.7 ; 5.5 \mathrm{Nexp}]$. For a general point of view, the main predicted lives are longer than experimental lifetimes. This fact is often observed in the literature [13]. To correct this, Sonsino et al. [16] propose to use a damage parameter to crack initiation $D$ (total Miner sum), smaller than 1 . 


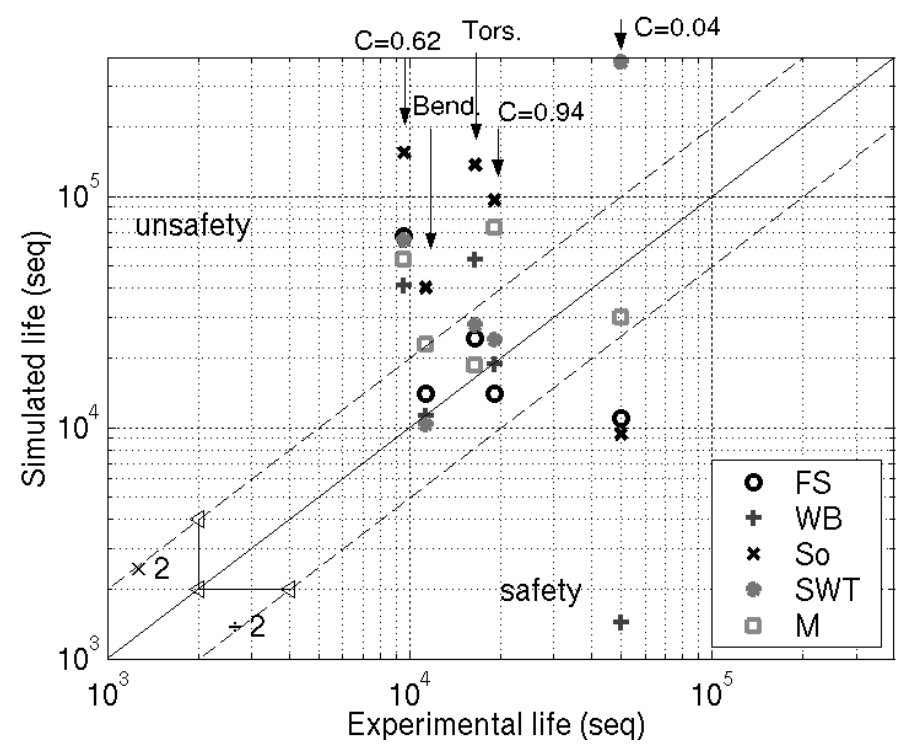

FIG. 7-Comparison between median experimental lives and simulated lives.

Table 3-Simulation results (Nf in number of sequences, $S W T=$ Smith-Watson-Topper, FS $=$ Fatemi-Socie, WB = Wang-Brown, So = Socie HCF, $M=$ Morel).

\begin{tabular}{cccccccc}
\hline Loading & $\mathrm{C}_{\mathrm{Mt}, \mathrm{Mb}}$ & $\mathrm{SWT}$ & $\mathrm{FS}$ & $\mathrm{WB}$ & $\mathrm{M}$ & $\mathrm{So}$ & $\mathrm{Nf}_{0.5}$ \\
\hline Torsion & $\ldots$ & 23965 & 14066 & 18830 & 73408 & 96308 & 19020 \\
Plane bending & $\ldots$ & 10297 & 14050 & 11180 & 22797 & 40403 & 11268 \\
Plane bend. + To & 0.04 & 380891 & 11019 & 1438 & 29946 & 9397 & 49760 \\
Plane bend + To & 0.62 & 64710 & 67650 & 41016 & 53070 & 155177 & 9587 \\
Plane bend + To & 0.94 & 27693 & 24333 & 53309 & 18492 & 137216 & 16496 \\
\hline
\end{tabular}

\section{Effect of the Correlation Factor on Life}

Figure 8 shows the experimental lives and the standard deviation of the experimental life (with lognormal distribution hypothesis) for our different fatigue tests under combined loadings. The number of tested specimens is indicated in brackets. According to this figure and due to the scatter of experimental lives (see standard deviation), the influence of the correlation factor on life is low for this material and our tests. Nevertheless, a synchronism shift seems to improve fatigue strength (around a median life factor of five between tests where $\mathrm{C}=0.04$, and $\mathrm{C}=0.94$ ). This observation also has been done on cast iron by Grubrisic [14] and Palin-Luc [10] under sinusoidal loading conditions. For the studied material, under constant amplitude multiaxial fatigue tests (bending and torsion), the phase shift effect on the fatigue limit improves the fatigue strength, but only $7 \%$ at $10^{6}$ cycles [17]. Shift of phase influence is often discussed in literature. For Sonsino, it is dependent on both the type of test (load or strain controlled) [18] and the material [19]: for ductile materials (structural steels), the shift of phase reduces the fatigue strength; semi-ductile materials (forged aluminium, cast steels) are not sensitive to the shift of phase, and the phase shift improves the fatigue strength of brittle materials (cast aluminium, cast iron, sintered steel). 


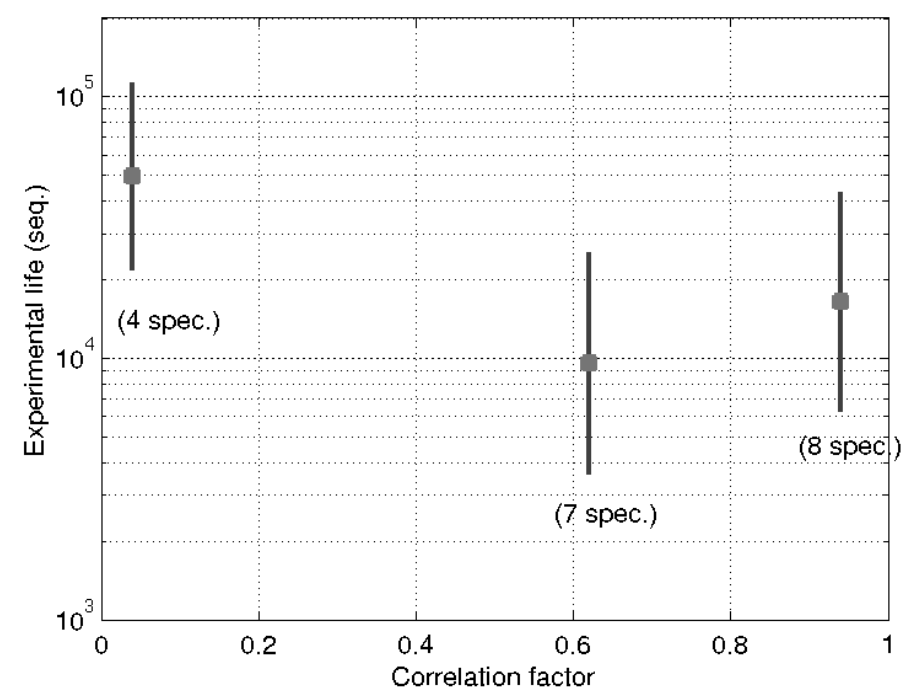

FIG. 8-Experimental life (in sequences) versus the correlation factor for fatigue tests in combined bending and torsion; $68 \%$ of the possible lives are in the interval illustrated by the vertical straight lines (standard deviation).

One reason for this low influence is proposed. The material used for machining the specimens is not completely brittle. Furthermore, fatigue tests were carried out under load control: that means that nominal stresses were controlled for each test, but local stresses were different. Elastic-plastic finite element analysis shows that local small plastic strains occurred in the specimens loaded under synchronous loadings. For synchronous combined bending and torsion tests $(C=0.94)$, the maximum Von Mises equivalent stress was equal to $391 \mathrm{MPa}$. This is higher than the corresponding value for uncorrelated tests $(C=0.04)$, for which the maximum Von Mises equivalent stress was $333 \mathrm{MPa}$. In this last case, total strains were smaller than under proportional fatigue tests $(C=0.94)$; thus, life may be a little bit longer than under synchronous tests.

\section{Conclusion and Prospects}

Random multiaxial fatigue tests (with stress controlled conditions) carried out on smooth specimens made of the EN GJS 800-2 spheroidal graphite cast iron show a low influence on the median life of the correlation factor between the bending and torsion loadings. This effect is not significant in middle high cycle fatigue if the scatter of experiments is considered. Local small plastic strains are pointed out to explain this. Comparison between fatigue data and simulations made with five fatigue life calculation methods shows that their predictions are good for proportional loadings, but there are large errors for non-proportional loadings, probably because most of the methods were proposed for ductile materials. Morel's proposal gives the best predictions for this SG cast iron and these tests. According to the fact that most of the predictions are unsafe, it seems prudent to use a damage parameter lower than 1 to predict crack initiation in design department. This point is in agreement with Sonsino's [16] conclusions.

The knowledge of the material behavior under non-proportional load paths always remains an open question, and research must progress in this way. Future work also must be done to develop a life prediction method adapted to non-proportional loading case. 


\section{References}

[1] Smith, J., Watson, P., and Topper, T., "A Stress Strain Function for Fatigue of Metals," Journal of Materials (JMLSA), 4, No. 5, 1970, pp. 293-298.

[2] Fatemi, A. and Socie, D., "A Critical Plane Approach to Multiaxial Fatigue Damage Including Out-of-Phase Loading," Fatigue and Fracture of Engineering Materials and Structures, 11, No. 3, 1988, pp. 149-165.

[3] Bannantine, J., "A Variable Amplitude Life Prediction Method," Ph.D. thesis, University of Illinois, Urbana-Champaign, 1989, p. 270.

[4] Bannantine, J. and Socie, D., "A Variable Amplitude Multiaxial Life Prediction Method," Fatigue under Biaxial and Multiaxial Loading, ESIS 10, K. Kussmaul, D. L. McDiarmid, and D.F. Socie, Eds., Mechanical Engineering Publication, London, 1991, pp. 35-51.

[5] Wang, C. and Brown, M., "Multiaxial Random Load Fatigue: Life Predictions Techniques and Experiments," Multiaxial Fatigue and Design, ESIS 21, A. Pineau and G. Cailletaud, Eds., Mechanical Engineering Publications, London, 1996, pp. 513-527.

[6] Wang, C. and Brown, M., "Life Prediction Techniques for Variable Amplitude Multiaxial Fatigue. Part I: Theories," Journal of Engineering Materials and Technology, 118, 1996, pp. 367-370.

[7] Socie, D., "Critical Plane Approaches for Multiaxial Fatigue Damage Assesment," Advances in Multiaxial Fatigue, ASTM STP 1191, D. L. McDowell and R. Ellis, Eds., ASTM International, West Conshohocken, PA, 1993, pp. 7-36.

[8] Morel, F., "A Critical Plane Approach for Life Prediction of High Cycle Fatigue under Multiaxial Variable Amplitude Loading," International Journal of Fatigue, 22, 2000, pp. 101-119.

[9] Morel, F., "Fatigue Multiaxiale Sous Chargement d'Amplitude Variable," Ph.D. thesis, ENSMA, Poitiers, France, 1996, p. 210.

[10] Palin-Luc, T., Lasserre, S., and Bérard, J-Y., "Experimental Investigation on the Significance of the Conventional Endurance Limit of a Spheroidal Graphite Cast Iron," Fatigue and Fracture of Engineering Materials and Structures, 21, 1998, pp. 191-200.

[11] Palin-Luc, T. and Lasserre, S., "Multiaxial Fatigue Testing Machine Under Variable Amplitude Loading of Bending and Torsion," Recent Advances in Experimental Mechanics, J. F. Silva Gomes et al., Eds., A. A. Balkema, Rotterdam, 1994, pp. 965-970.

[12] Banvillet, A., "Prévision de Durée de Vie en Fatigue Multiaxiale Sous Chargements Réels: Vers des Essais Accélérés," Ph.D. Thesis, ENSAM, Bordeaux, France, 2001, p 204.

[13] Lagoda, T., Macha, E., Nieslony, A., and Müller, A., "Fatigue Life of Cast Irons GGG40, GGG60 and GTS45 Under Combined Random Tension with Torsion," Fracture Mechanics: Application and challenges, M. E. M. Fuentes and A. Martin-Meizoso, Eds., ECF13, San Sebastian, Spain, 2000, on CD-Rom.

[14] Grubisic, V., "Festigkeitsverhalten von Sphärogub bei Kombinierter Statischer und Dynamischer Mehrachsiger Beanspruchung," Tech. Rep., LBF-Fraunhofer Institute, Darmstadt, Bericht Nr. FB-149, 1979.

[15] Kim, K. S. and Park, J. C., "Shear Strain Based Multiaxial Fatigue Parameters Applied to Variable Amplitude Loading," International Journal of Fatigue, 21, 1999, pp. 475-483.

[16] Sonsino, C. M., Kaufman H., and Grubisic, V., "Transferability of Material Data for the Example of a Randomly Loaded Truck Stub Axle," SAE Tech. paper series, 970708, 1997, pp. 1-22. 
[17] Palin-Luc, T. and Lasserre, S., "An Energy Based Criterion for High Cycle Multiaxial Fatigue," European Journal of Mechanics, A/Solids, 17, No. 2, 1998, pp. 237-251.

[18] Sonsino, C. M., "Influence of Load and Deformation-Controlled Multiaxial Tests on Fatigue Life to Crack Initiation," International Journal of Fatigue, 23, 2001, pp. 159167.

[19] Sonsino, C. M. and Kueppers, M., "Fatigue Behavior of Welded Aluminium Under Multiaxial Loading," In: Proceedings of the $6^{\text {th }}$ International Conference on Biaxial/Multiaxial Fatigue \& Fracture, M. M. de Freitas, Ed., ESIS, Lisboa, Portugal, 2001, pp. 57-64.

\section{Appendix}

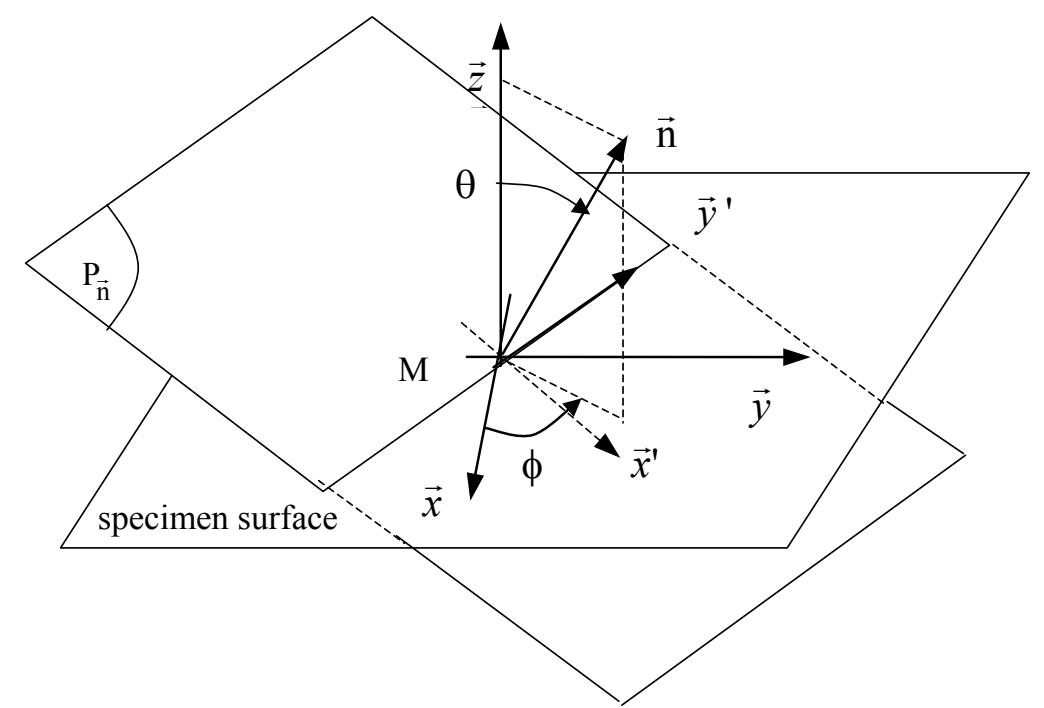

$(\vec{x}, \vec{y}, \vec{z})$ cartesian coordinates system linked with the specimen surface.

$\left(\vec{x}^{\prime}, \vec{y}^{\prime}, \vec{n}\right)$ cartesian coordinates system linked with de plane $\mathrm{P}_{\overrightarrow{\mathrm{n}}}$ orientated by $\overrightarrow{\mathrm{n}}$.

FIG. A.1-Coordinate systems used to define the unit normal vector $\overrightarrow{\mathrm{n}}$ orientating each material plane $\mathrm{P}_{\overrightarrow{\mathrm{n}}}$ at the point $M$ on the surface of the specimen. 